\title{
Induced Orientational Order in Long Alkyl Chain Aminosilane Molecules by Preadsorbed Octadecyltrichlorosilane on Hydroxylated $\mathrm{Si}(100)^{\dagger}$
}

\author{
P. Harder, K. Bierbaum ${ }^{\ddagger}$ Ch. Woell, and M. Grunze* \\ Institut für Angewandte Physikalische Chemie, Im Neuenheimer Feld 253, \\ 69120 Heidelberg, Germany \\ S. Heid and F. Effenberger \\ Institut für Organische Chemie und I sotopenforschung, Pfaffenwaldring 55, \\ 70569 Stuttgart, Germany
}

Received May 20, 1996. In Final Form: October 15, $1996^{\otimes}$

\begin{abstract}
We studied the adsorption of (17-aminoheptadecyl)trimethoxysilane (AHTMS; $\mathrm{NH}_{2}\left(\mathrm{CH}_{2}\right)_{17} \mathrm{Si}\left(\mathrm{OCH}_{3}\right)_{3}$ ) onto hydroxylated $\mathrm{Si}(100)$ wafers, which were preexposed to methyl-terminated n-octadecyltrichl orosilane (OTS; $\mathrm{CH}_{3}\left(\mathrm{CH}_{2}\right)_{17} \mathrm{SiCl}_{3}$ ) for various immersion periods, resulting in partial coverages between $42 \%$ and $88 \%$ of a complete monolayer. Preadsorption of a partial monolayer of OTS was found to drastically improve the molecular alignment of subsequently adsorbed AHTMS. This effect was observed for submonolayer OTS films exhibiting both an island or a homogeneous growth mode, as determined by atomic force microscopy. Without preadsorbed OTS, the adsorption of AHTMS from an aged solution typically resulted in films of multilayer thickness, while the use of fresh solutions of AHTMS resulted in disordered films of submonolayer coverage. We suggest that submonolayer quantities of preadsorbed OTS prevent coagulated ami nosilaneadsorption and enableoriented adsorption of ami nosilanemol ecules al ong the domain perimeter of aligned and ordered methyl-terminated silane. In comparison to sequential adsorption, coadsorption of n-octadecyltrimethoxysilane $\left(\mathrm{OTMS} ; \mathrm{CH}_{3}\left(\mathrm{CH}_{2}\right)_{17} \mathrm{Si}\left(\mathrm{OCH}_{3}\right)_{3}\right)$ with AHTMS from a mixture gave films of low quality. The OTS/AHTMS surface that was prepared by sequential adsorption was exposed to pentafluorobenzaldehyde (PFBA) to probe the reactivity and orientation of the AHTMS amino groups. Eighteen to thirty-four percent of the amine groups reacted with no or minor disturbance to the mol ecular order, compared to $21-44 \%$ on pure and disordered AHTMS multilayers. This indicates that the coupling reaction with PFBA in toluene involves only part of the amino groups at the interface.
\end{abstract}

\section{Introduction}

It is well-known that n-octadecyltrichlorosilane (OTS) forms self-assembled highly ordered monolayers on a variety of substrates. ${ }^{1-5}$ Due to a lack of reactive tail groups, OTS cannot be used for covalent coupling reactions, e.g., reaction with an aldehyde for antibody immobilization in biosensor applications. ${ }^{6}$ Long alkyl chain (17-aminoheptadecyl)trimethoxysilane (AHTMS) aminosilane films have the desired functional ity for further reactions and wereinvestigated in terms of their molecular order, film thickness, and composition. ${ }^{7}$ We found, however, that AHTMS aminosilanefilms having thesame alkyl chain length as OTS show nopreferential molecular orientation with respect to the substrate surface. This is presumably caused by chemical interactions between amino and silanol groups, as inferred from X-ray photoelectron spectroscopy (XPS) and infrared (IR) spectroscopy

* Corresponding author Fax: +49-6221-546199. Phone: +496221-548461. E-mail: grunze@sun0.urz.uni-heidelberg.de.

† This paper is dedicated to Professor R. Gleiter on the occasion of his 60th birthday.

₹ Present address: Sika AG, Tuffenwies 16-22, CH-8048Zurich.

$\otimes$ Abstract published in AdvanceACS Abstracts, J anuary 1, 1997.

(1) Sagiv, J. J . Am. Chem. Soc. 1980, 102, 92-98.

(2) Wasserman, S. R.; Tao, Y.-T.; Whitesides, G. M. Langmuir 1989, 5, 1074-1087.

(3) Tillman, N.; UIman, A.; Schildkraut, J . S.; Penner, T. L. J . Am. Chem. Soc. 1988, 111, 6136-6144.

(4) Pomerantz, M.; Segmüller, A.; Netzer, L.; Sagiv, J . Thin Solid Films 1985, 132, 153-162.

(5) Parikh, A. N.; Allara, D. L. J . Phys. Chem 1994, 98, 7577-7590.

(6) Dahint, R.; Grunze, M.; J osse, F.; Renken, J . Anal. Chem. 1994, 66, 2888-2892.

(7) Bierbaum, K.; Kinzler, M.; Wöll, Ch.; Grunze, M.; Hähner, G.; Heid, S.; Effenberger, F. Langmuir 1995, 11, 512-518. measurements, 7,8 which gives evidence for the presence of free, hydrogen-bonded, and protonated amino groups in the films.

In this paper we report results showing that a preferential molecular orientation of AHTMS molecules can be achieved by templating topreadsorbed OTS. Coadsorption of OTS and long chain substituted cyanine dyes was the first method employed to investigate the orientation of the alkyl chains in the film. ${ }^{9}$ Voids in the OTS films due to solvent retention of hexadecane and its release by rinsing with chloroform could be filled in with octadecanamine and octadecanoic acid ${ }^{10}$ or with OTS itself. ${ }^{11}$ Dilution with the corresponding methyl-terminated trichlorosilanes or backfilling was found to solidify mixed monolayers with a long chain 2-naphthyl-tagged nalkyltrichl orosilane. $^{12}$

The concept of using lateral templating to induce orientational order in otherwise disor dered systems came from our previously reported observation that OTS forms islands in the submonolayer coverage range with a high preferential molecular order. 7,15 Supported by our recent Monte Carlo calculation on the phase behavior in selfassembling alkane monolayers, ${ }^{13}$ this can be explained

(8) Culler, S. R.; Ishida, H.; Koenig, J . L. J . Colloid Interface Sci. 1985, 106 (2), 334-346.

(9) Sagiv, J. J . Am. Chem. Soc. 1980, 102, 92-98.

(10) Kallury, K. M. R.; Thompson, M.; Tripp, C. P.; Hair, M. L. Langmuir 1992, 8, 947.

(11) Gun, J .; Sagiv, J . J . Colloid Interface Sci. 1986, 112 (2), 457472.

(12) Mathauer, K.; Frank, C. W. Langmuir 1993, 9, 3002-3008. 3489. 
by a high lateral mobility of the adsorbed molecules and a two-dimensional condensation of ordered domains, driven by theattractivevan der Waal s interaction between the alkane chains of ca. $2 \mathrm{kcal} / \mathrm{mol}$ per methylene unit. Hence, if thelateral attractivevan der Waals interactions between the al kane chains can energetically compensate for the acid/base interactions between the amine groups of AHTMS and the surface silanol groups, a lateral templating leading to oriented AHTMS should bepossible.

As will beshown, there exists another important factor besides lateral templating which contributes to ordered monolayer growth, i.e., the inhibition of coagulated AHTMS particleadsor ption fromsolution by preadsorbed OTS. This indicates that partial hydrophobization of the silanol surface protects the surface from coagulated AHTMS and, hence, from multilayer adsorption.

\section{Experimental Section}

Sample Preparation. n-Octadecyltrichlorosilane, OTS (Merck, >98\%), octadecyltrimethoxysilane, OTMS (Fluka, 90\%), pentafluorobenzal dehyde, PFBA (Aldrich, 98\%), and bicyclohexyl (Fluka, >99\%) were used as received. The synthesis of (17aminoheptadecyl)trimethoxysilane(AHTMS) has been described previously. ${ }^{14} \mathrm{H}_{2} \mathrm{SO}_{4}, 30 \% \mathrm{H}_{2} \mathrm{O}_{2}$, toluene, and chloroform were of analytical quality.

The substrates of $1.5 \mathrm{~cm} \times 2 \mathrm{~cm}$ size were cut from doublesided polished, $0.5 \mathrm{~mm}$ thick $\mathrm{Si}(100)$ wafers. Prior to film preparation, the substrates were cleaned by a wet chemical treatment in a freshly prepared hot acid mixture (3:1 v/v mixture of $\mathrm{H}_{2} \mathrm{SO}_{4}$ and $30 \% \mathrm{H}_{2} \mathrm{O}_{2}$ at $\sim 80{ }^{\circ} \mathrm{C}$, caution: this mixture reacts viol ently with organic materials and must behandled with great care) for $1 \mathrm{~h}$ foll lowed by an extensive rinsewith ultraclean water (Millipore) and blown dry with nitrogen. Film preparation of complete OTS films was performed by immersing the $\mathrm{Si}$ substrates for $24 \mathrm{~h}$ in a $1 \mathrm{mM}$ OTS solution in bicyclohexyl. The trimethoxysilane (AHTMS and n-octadecyltrimethoxysilane, OTMS) films were prepared from a $0.1 \mathrm{M}$ bicyclohexyl solution. To remove excess silane aggregates, the samples were rinsed with Millipore water, stirred in a chloroform bath for several minutes, and blown dry. If there was still some excess polymer visible under a fiber optical illuminator, the samples were wiped with a soft $100 \%$ cotton cl oth (TX 304, TexwipeCo., U pper Saddle River, NJ ) which was dipped in chloroform.

OTS submonolayer films were prepared by preadsorption of OTS for 15,60 , or $120 \mathrm{~s}$, followed by thetreatment with Millipore water and chlor oform. Afterward, one of the identically treated samples was treated with an AHTMS solution for $24 \mathrm{~h}$, others were examined using AFM, IR spectroscopy, XPS, and nearedge X-ray absorption fine structure spectroscopy (NEXAFS).

Pentafluorobenzaldehyde was used in the form of a $0.1 \mathrm{M}$ solution in toluene. After a $24 \mathrm{~h}$ immersion period, the samples were rinsed with water and toluene and wiped with a cotton cloth. For further details of the sample preparation, see refs 7 and 15.

XPS. The XPS experiments were carried out on a Leybold MAX-200 spectrometer using a Mg K $\alpha$ X-ray source operating at $300 \mathrm{~W}$ power consumption. The pressure in the XPS system during the measurements was better than $10^{-9}$ mbar. Survey spectra were recorded prior to and after the XPS experiments in order to check for beam damage in the films. No changes due to X-ray exposure could be detected in the survey spectra for the experimental conditions applied. Spectra were recorded in the normal emission mode and were normalized for constant transmission using the software supplied by the manufacturer, and el ectron binding energies were calibrated against the alkyl $\mathrm{C}$ 1s emission peak at $\mathrm{E}_{\mathrm{b}}=284.6 \mathrm{eV}$. The attenuation of the $\mathrm{Si}$ 2p peak of thesubstratesilicon was used to determinetheaverage thickness of the adsorbed layers, assuming an electron mean free path of $34 \AA .{ }^{7}$ The attenuation of the substrate signal is different for a film of uniform thickness, as compared to a submonolayer film with island formation. For a uniform film,

(14) Effenberger, F.; Heid, S. Synthesis 1995, 1126-1130.

(15) Bierbaum, K.; Baski, A. A.; Chi, L. F.; Schrepp, W.; Fuchs, H.; Grunze, M. Langmuir 1995, 11, 2143-2150.
Table 1. Mixed OTS/AHTMS Samples

\begin{tabular}{|c|c|c|c|}
\hline sample & $\begin{array}{l}\% \text { preadsorption } \\
\text { of OTS normalized } \\
\text { to full OTS } \\
\text { monolayer (100\%) }\end{array}$ & growth mode & $\begin{array}{l}\% \text { normalized } \\
\text { coverage after } \\
\text { subsequent } \\
\text { adsorption } \\
\text { of AHTMS }\end{array}$ \\
\hline A & $88-93^{a, b}$ & $\begin{array}{l}\text { OTS islands, } \\
\sim 0.8 \mu \mathrm{m} \text { diameter }\end{array}$ & $110^{\mathrm{a}}$ \\
\hline B & $45-54^{b}$ & $\begin{array}{l}\text { OTS islands, } \\
\sim 0.1 \mu \mathrm{m} \text { diameter }\end{array}$ & 87 \\
\hline $\begin{array}{l}\text { C } \\
D\end{array}$ & $\begin{array}{l}42 \\
64\end{array}$ & $\begin{array}{l}\text { homogeneous } \\
\text { homogeneous }\end{array}$ & $\begin{array}{r}89 \\
100\end{array}$ \\
\hline $\mathrm{E}$ & 74 & homogeneous & 100 \\
\hline
\end{tabular}

a The data include some physisorbed OTS which was not, but could be, removed by wiping with a cotton cloth. ${ }^{b}$ The normalized precoverages were calculated from the attenuation of the XPS Si $2 p$ substrate signal. For the island growth mode submonolayers, the real precoverage is between the lower value calculated for a film of homogeneous thickness and the higher value calculated assuming islands of fully extended OTS chains.

the substrate signal decreases exponentially with the film thickness, while the attenuation is directly proportional to the coveragefor an island growth mode. Theuniform overlayer gives a somewhat higher attenuation than that of an island film with the same average thickness, as indicated in Table 1 . The difference is a function of the electron mean free path through the specific adsorbate and decreases with increasing coverage. Hence, the real average thickness will be within the lower limit calculated for a uniform film and the higher limit for a film with islands of fully extended OTS molecules with their chain axes perpendicular to the surface plane.

$\mathrm{C}: \mathrm{N}: \mathrm{F}$ stoichiometries were calculated from detailed spectra of the corresponding 1 s peaks, using relative sensitivity factors of $1: 1.77: 3.28$, as determined for the MAX-200 spectrometer, and a linear background subtraction routine.

FTIR. The normal transmission and Brewster angle IR spectra weretaken with a F ourier transform spectrometer (M odel IF S-66v, Bruker, Germany) at $4 \mathrm{~cm}^{-1}$ resolution. The resulting interferograms wereF ourier transformed with Blackman-Harris 3-term apodization. ${ }^{16}$ The point density in the spectra was increased with zero-filling ${ }^{17}$ by a factor of 8 . All spectra were ratioed against referencespectra of d eaned sil icon samples from the same wafer. For complete, ordered monolayers, the discrepancy in the $\mathrm{d}^{ \pm}$peak positions between two individual measurements was ca. $\pm 0.2 \mathrm{~cm}^{-1}$. Spectra of submonolayer and disordered films with weak, broad bands aremore sensitive with respect to the slight variations of the spectrometer optics and the cleaning of the silicon samples used for the background spectra. At $\sim 40 \%$ coverage, we observed variations of up to \pm 1 $\mathrm{cm}^{-1}$ in the band widths and $\pm 0.5 \mathrm{~cm}^{-1}$ in the peak positions as a consequence of a change of the reference sample.

The transmission of an IR beam through a silicon wafer with two parallel sides causes sinusoidal modulations (fringes) on the base line of the IR spectra. The periodicity of the fringes is inversely proportional to the thickness of the wafer. For the 0.5 $\mathrm{mm}$ thick Si wafer used in the present study, the maximum possibleresolution for which thefringes are not resolved islimited to about $4 \mathrm{~cm}^{-1}$. Experimentally, the problem of interferences can besolved by wafers with nonparallel sides ${ }^{5}$ or by performing measurements in the Brewster angle $\left(\theta_{\mathrm{B}}\right)$ configuration, ${ }^{18}$ i.e., using a $\mathrm{p}$-polarized IR beam incident to the surface at the Brewster's angle $\left(\theta_{\mathrm{B}}=73.7^{\circ}\right.$ for $\mathrm{Si}$ with an index of refraction of 3.42). The latter method offers the advantage that at neargrazing incidence, vibrations perpendicular to the surface will beenhanced relative to vibrations parallel to thesurface. Thus, the dichroic ratio $\mathrm{A}\left(\theta_{\mathrm{B}}\right) / \mathrm{A}\left(0^{\circ}\right)$ for each absorption band is a measure for the average orientation in the thin organic film. With the sample mounted on a rotary stage, spectra in both configurations can be obtained. In the Brewster angle configuration, we use a p-polarized IR beam with a diameter of about $2 \mathrm{~mm}$, and in normal transmission, theKRS-5 wiregrid polarizer is removed.

(16) Gronholz, J .; Herres, W. Instrum. Comput. 1985, 3, 10-15.

(17) Gronholz, J .; Herres, W. Comp. Appl. Lab. 1984, 2, 216-222.

(18) Maoz, R.; Sagiv, J . Proceedings of I nternational Symposium on Functional Langmuir-Blodgett Films, Tokyo, J uly 1992; pp 23-33. 


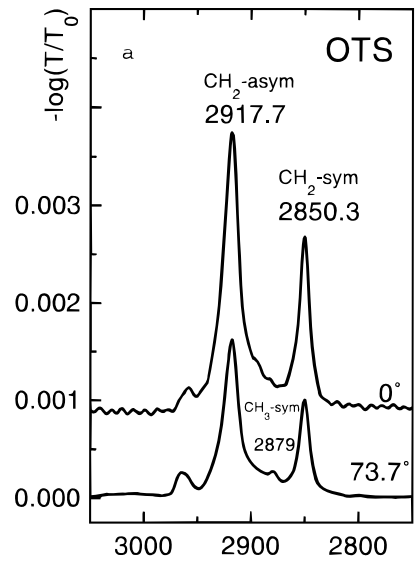

Wavenumbers $\left[\mathrm{cm}^{-1}\right]$

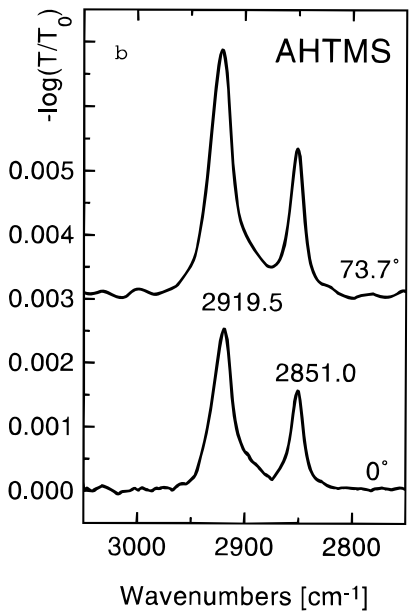

Wavenumbers $\left[\mathrm{cm}^{-1}\right]$
F igure 1. IR spectra of (a) a complete OTS monolayer and (b) a AHTMS film of about bilayer thickness in the normal transmission $\left(0^{\circ}\right)$ and Brewster angleconfiguration $\left(73.7^{\circ}\right)$. For OTS, the reduction of the methylene bands at 2917 and 2850 $\mathrm{cm}^{-1}$ as well as the increase of the $\mathrm{CH}_{3}$ sym band at $2877 \mathrm{~cm}^{-1}$, when going from normal to glancing transmission, indicate an ordered film. AHTMS methylene peak positions of 2919.6 and $2850.9 \mathrm{~cm}^{-1}$ indicatea reduced but still partly existing molecular alignment, while dichroic ratios in a range from 1.1 to 1.6 indicate an average tilt angle of about $38-51^{\circ}$.

Normal transmission and Brewster's angle transmission spectra of monolayer OTS films gave peak positions of 2917.7 $\mathrm{cm}^{-1}$ for themethylene $\mathrm{C}-\mathrm{H}$ antisymmetric $\left(\mathrm{d}^{-}\right)$modeand 2850.3 $\mathrm{cm}^{-1}$ for the symmetric $\left(\mathrm{d}^{+}\right)$mode, as shown in Figure la. These values are within the range of the peak positions reported previously by others ${ }^{2,3,19}$ and are interpreted as characteristic for all-trans alkyl chains in a crystalline-like phase. Despitean increase in the optical pathway when going from normal to glancing transmission, the band heights of both of themethylene stretching modes decreaseto about $55 \%$ of their height in normal transmission. Noteal sothepresence of the $\mathrm{CH}_{3}$ symmetricmode at $2879 \mathrm{~cm}^{-1}$ in glancing transmission. This band is hardly visible in normal transmission spectra, as expected for a vibrational modewith an essentially perpendicular orientation tothesurface plane.

For a quantitative interpretation of the dichroic ratios, we simulated the data with a matrix method described by Parikh and Allara. ${ }^{20}$ With this method, the optical properties of the organic film are derived from the bulk spectra of a suitablemodel compound. For the simulation of a crystallinelike ordered $\mathrm{C}_{18}$ film, we chose the bulk spectrum of crystalline n-octadecyl disulfide ${ }^{21}$ as an isotropic reference for an all-trans al kane chain with 17 methyleneunits. This method has been used previously for a quantitative interpretation of OTS film spectra on silicon surfaces in external reflection geometry. ${ }^{22}$ We do not daim that the bulk spectra of a long alkyl disulfide is a valid reference spectra for the methyleneabsorption bands of submonolayers of OTS and AHTMS samples because a set of different monofunctional longalkyl chain molecules shows differences in band widths and intensities. ${ }^{5}$ Theratio of the IR band intensities in glancing and normal transmission, that we use for a calculation of the average tilt angle, is less affected by such variations in band widths and band intensities. Note that the dichroic ratios for theantisymmetricand thesymmetricmethylenestretchingmode are nearly identical.

Thetwist angle, which effects theratiobetween thesymmetric and antisymmetric methylene stretching bands for any nonnormal orientation, was fixed at $45^{\circ}$. Hence, in agreement with the experimental results, the angle between the transition moment and the surface normal was always identical for both the symmetric and antisymmetric vibrations.

(19) Maoz, R.; Sagiv, I J . Colloid InterfaceSci. 1984, 100, 465-496.

(20) Parikh, A. N.; Allara, D. L. J . Chem. Phys. 1992, 96, 927-945.

(21) Laibinis, P. E.; Whitesides, G. M.; Allara, D. L.; Tao, Y.-T.; Parikh, A. N.; Nuzzo, R. G. j . Am. Chem. Soc. 1991, 113, 7152-7167.

(22) Hoffman, H.; Mayer, U.; Krischanitz, A. Langmuir 1995, 11, 1304-1312.

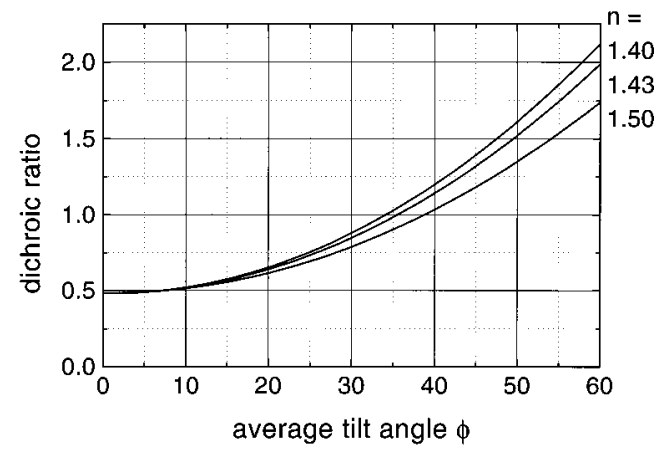

Figure 2. Dichroicratio, i.e., band height for $\mathrm{CH}_{2}$ asym in the Brewster angle configuration divided by the band height in the normal transmission configuration, as calculated from spectra simulations as a function of the tilt angle $\phi$ between the chain axis and the surface normal for a refractive index of 1.40, 1.43, and 1.50 .

The real part of each complex tensor element of the organic layer was obtained by an appropriate Kramers-Kronig transformation, assuminga refractiveindex of 1.43 in thenonabsorbing regions as it was found for pureliquid and crystalline paraffins. ${ }^{23}$ Becausethematrix method takes intoaccount multipler eflections at the front and back $\mathrm{Si}$-air interface, the spectra simulations show sinusoidal modulations when thethickness of thesubstrate is a multiple of $\lambda / 2$ in the respective medium. To eliminate interferencefringes from our cal culations, weused thereflectance ( $r$ ) and transmittance (t) coefficients that werre calculated with the matrix method for an air-Si and $\mathrm{Si}$-air interface in combination with the dassical formula describing the fraction of power transmitted (T) when thereis no coherence between the two interfaces.

$$
\begin{array}{r}
T=\left|t_{13}\right|^{2} \cdot\left|t_{31}\right|^{2}+\left|t_{13}\right|^{2} \cdot\left|r_{31}\right|^{4} \cdot\left|t_{31}\right|^{2}+\left|t_{13}\right|^{2} \cdot\left|r_{31}\right|^{8} \cdot\left|t_{31}\right|^{2}+\ldots= \\
\frac{\left|t_{13}\right|^{2} \cdot\left|t_{31}\right|^{2}}{1-\left|r_{31}\right|^{4}}
\end{array}
$$

Calculating the coefficients $t_{13}, t_{31}$, and $r_{31}$ in the presence of theorganicfilm (medium2) and for thefilm-freeinterfaceresulted in fringe-free spectra simulations without ignoring the contribution of themultipleinternal reflections totheabsorbancespectra in normal transmission. As a result, spectra simulations for a $26 \AA$ thick layer of oriented alkanechains in normal transmission and in the Brewster angle configuration resulted in the relationship of the dichroic ratio of the methylene $\mathrm{C}-\mathrm{H}$ antisymmetric stretching band and the molecular tilt angle $\phi$ shown in Figure 2. The dichroic ratio $A\left(73.7^{\circ}\right) / A\left(0^{\circ}\right)$ for the $d^{-}$mode of 0.55 for OTS monolayers corresponds to an average tilt angle, $\phi$, of $13^{\circ}$, in good agreement with earlier findings of $10-18^{\circ}, 30-10^{\circ}, 78^{\circ}, 22$ and $11^{\circ} .^{5}$

No correction was made for the experimental angular spread of $\pm 5^{\circ}$ of the angle of incidence because the deviations from the Brewster angle were symmetric, so that the deviation for an angle of incidence greater than that calculated will mainly be compensated for by the deviation caused by a smaller angle of incidence.

NEXAFS. The NEXAFS spectra were recorded at the synchroton radiation facility BE SSY in Berlin using a HE-TGM 2 monochromator. For the experimental details and a brief description of the method, see ref 7. X-ray absorption spectra at the $C$ 1s edge are domi nated by a $C$ is $\rightarrow$ Rydberg states $(R)$ resonance at $287.7 \mathrm{eV}$ and a C $1 \mathrm{~s} \rightarrow \sigma^{*}$ resonance at $293 \mathrm{eV}$. The $C$ Is $\rightarrow \sigma^{*}$ resonance is polarized along the molecular axis of OTS, and thetransition dipolemoment of the $\mathrm{C} 1 \mathrm{~s} \rightarrow \mathrm{R}$ resonance is orthogonal to the $\mathrm{C}$ 1s $\rightarrow \sigma^{*}$ transition dipole. ${ }^{24}$ From the variation of these two resonances with the angle of incidence, $\theta$, of thephotons, theaverageorientation of theel ectronictransitions

(23) CRC Handbook of Chemistry and Physics, 56th ed.; Weast, R. C., Ed.; CRC Press: Cleveland, OH, 1975.

(24) Bagus, P. S.; Weiss, K.; Schertel, A.; Wöll, Ch.; Braun, W.; Hellwig, C.; J ung, C. Chem. Phys. Letters 1996, 248, 129-135. 
can becalculated within thedipoleapproximation and interpreted with a model of uniformly tilted all-trans alkyl chains.

AFM. The OTS growth behavior (island or homogeneous growth mode) was investigated under ambient conditions with a Park Scientific Autoprobe CP system with a $5 \mu \mathrm{m}$ scanner. Constant force images were taken in the repulsive mode with a silicon nitride cantilever having an integrated pyramidal tip. Typical forces were on the order of $10 \mathrm{nN}$, using a $200 \mu \mathrm{m}$ long cantilever with a spring constant of $0.06 \mathrm{~N} / \mathrm{m}$.

\section{Results}

Neat AHTMS Films. The properties of neat AHTMS films were not found to be reproducible in a quantitative sense; they exhibit strong variations with age and appearance of the AHTMS solution from charge to charge. The presence of the nucleophilic amine group in the moleculepromotes the polymerization of thealkoxysilane in solution. Thus, both surface reaction and polymerization in solution occur simultaneously during immersion of the sample. ${ }^{25}$ A clear AHTMS solution in bicyclohexyl resulted in films with submonolayer to monolayer coverage. IR spectra of thesesubmonolayer AHMTS films show $\mathrm{d}^{-}$and $\mathrm{d}^{+}$mode peaks at 2924 and $2854 \mathrm{~cm}^{-1}$, respectively, values which approach those that are associated with highly conformationally disordered chain assemblies. ${ }^{26}$

Adsorption from an initially cloudy solution always resulted in coverages exceeding one monolayer. Physisorption of polymerized silane molecules was also observed for OTS films, but excess adsorption could be completely removed by wiping with a cotton cloth. Contrary, in the case of AHTMS, polycondensate adsorption was resistant to extensive water and chloroform rinsing and wiping. In comparison to AHTMS submonolayer films, themethylenestretching modes in theAHTMS multilayer film spectra weresigni ficantly shifted to lower wavenumbers. The measured absorption maxima, in normal transmission, in the rangefrom 2919 to $2920 \mathrm{~cm}^{-1}$ and about $2851 \mathrm{~cm}^{-1}$ show that the average chain conformation is neither all-trans nor liquid-likedisordered. Note that oppositeto the behavi or of complete OTS films, the absorption bands increased when going from normal to glancing transmission (Figure 1b). Because the thickness of theneat AHTMS multilayer films was not constant over the whole sample and the IR beam spot size was not thesamefor normal $\left(\sim 3 \mathrm{~mm}^{2}\right)$ and glancing transmission $\left(\sim 11 \mathrm{~mm}^{2}\right)$, different measurements for the dichroic ratio were scattered in a broad range from 1.1 to 1.6. Interpretation with theoptical function of $n$-octadecyl disulfide results in tilt angles between $38^{\circ}$ and $51^{\circ}$, consistent with an almost random orientation. NEXAFS spectra (Figure 3) of neat AHTMS films, in contrast to spectra of neat OTS films, did not vary with the angle of incidence, ${ }^{7}$ corresponding toeither a uniformtilt anglenear themagic angle of $54.7^{\circ}$ or a random distribution of the transition dipole moments.

In the lower wavenumber range, the IR spectrum (Figure4) of a neat AHTMS film (thickness ca. $50 \AA$ ) shows two strong bands at 1636 and $1540 \mathrm{~cm}^{-1}$ besides the methylene scissoring band at $1467 \mathrm{~cm}^{-1}$. Broad bands at 1640 and $1568 \mathrm{~cm}^{-1}$ were al so found $\mathrm{d}^{27}$ in the spectra of physisorbed multilayers of (3-aminopropyl)triethoxysilane on $\mathrm{Au}$ after exposure to ambient conditions and were assigned to ammonium bicarbonate formation, and we propose the same assignments of the bands at 1636 and $1540 \mathrm{~cm}^{-1}$ in our experiments.

The XPS spectra of the $N$ is region of neat AHTMS films (Figure 5) show an asymmetric broad band, which

(25) Tripp, C. P.; Hair, M. L. J . Phys. Chem. 1993, 97, 5693-5698. (26) Snyder, R. G.; Strauss, H. L.; Elliger, C. A.J . Phys. Chem. 1982, $86,5145-5150$.

(27) Kurth, D. G.; Bein, T. Langmuir 1995, 11, 3061-3067.
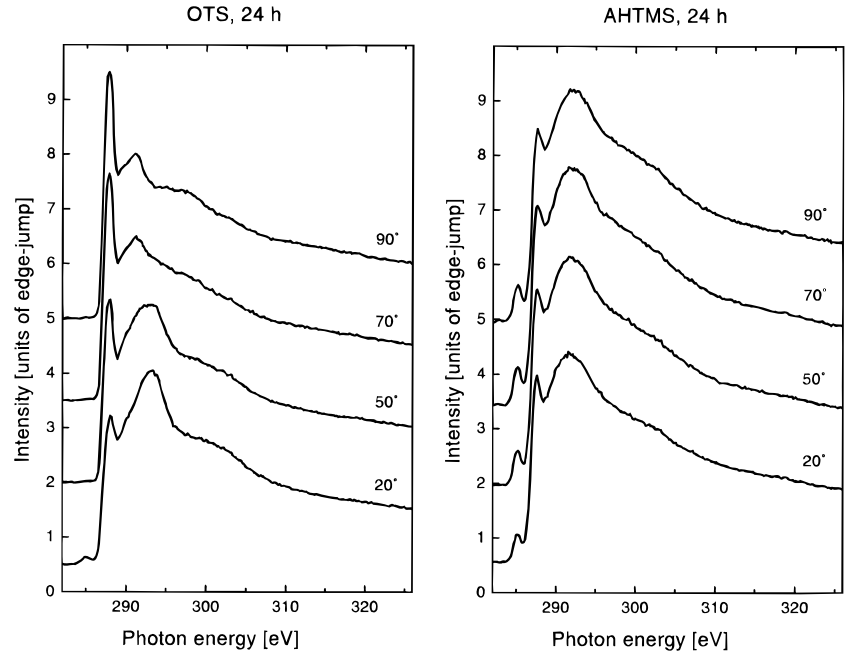

Figure 3. Series of NEXAFS spectra for OTS (left) and AHTMS (right) for different angles of incidence ranging from 20 to $90^{\circ}$.

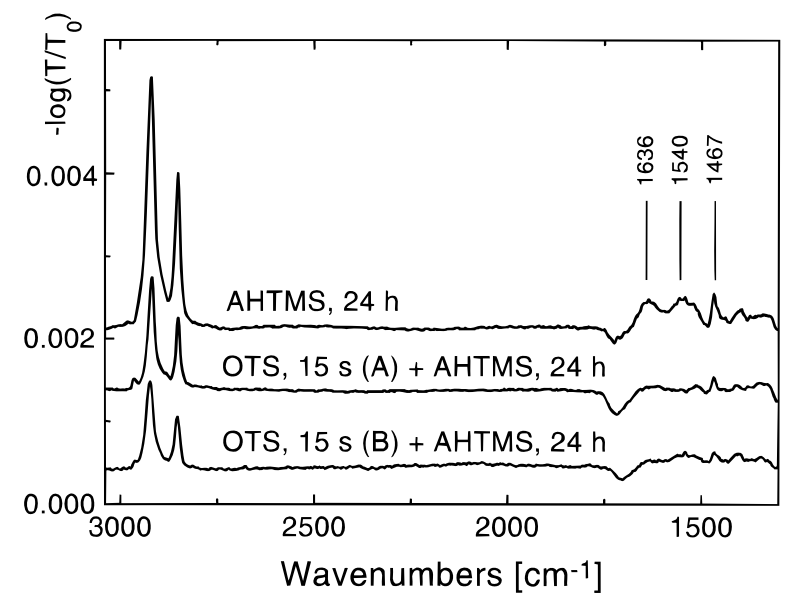

Figure 4. Glancing transmission spectra showing the region between 3000 and $1300 \mathrm{~cm}^{-1}$ of a neat AHTMS sample (upper curve) and the two OTS/AHTMS films A and B (Table 1). Negative absorption bands at ca. $1720 \mathrm{~cm}^{-1}$ are due to a selfcleaning effect of the adsorption process reducing the amount of carbonic acid and ester contaminations on the silicon surface.

can be fit by a peak ascribed to the $\mathrm{NH}_{3}{ }^{+}$species with a binding energy of ca. $402 \mathrm{eV}^{28}$ and two peaks ascribed to hydrogen bonded and free $\mathrm{NH}_{2}$ groups at 400-401 and $399 \mathrm{eV}$, respectively. ${ }^{10}$

Both $\mathrm{CO}_{2}$ dissolved in $\mathrm{H}_{2} \mathrm{O}\left(\mathrm{pK}_{a} 6.35\right)^{29}$ and the surface $\mathrm{SiOH}$ groups $\left(\mathrm{pK}_{\mathrm{a}} \sim 7.1\right)^{30}$ are acidic enough to protonate theaminegroup (the $\mathrm{pK}_{\mathrm{a}}$ of a long alkyl chain ammonium group is $\sim 10-11){ }^{31}$ The $\mathrm{Si}-\mathrm{OH}$ groups of hydrolyzed, but not polymerized, silane head groups areabout 4 orders of magnitude less acidic than surface silanol groups and associate via hydrogen bonds. The relative amount of the different species that were observed in the XPS spectra was determined with a peak fitting routine assuming Gaussian peak shapes with predetermined peak positions $(401.8,400.3$, and $399.3 \mathrm{eV})$ and halfwidths of $1.6 \mathrm{eV}$. F or two samples with bilayer thickness (Figure $5 a, b)$, prepared from thesameAHTMS stock solution, the percentage of the protonated nitrogen species was about

(28) Wagner, C. D.; Riggs, W. M.; Davis, L. E.; Moulder, J . F.; Muilenberg, G. E. Handbook of X-ray photoel ectron spectroscopy; PerkinElmer Corporation: Eden Prairie, MN.

(29) Wiberg, N. Lehrbuch der anorganischen Chemie91-100th ed.; Walter de Gruyter: Berlin, 1985; p 241.

(30) Tripp, C. P.; Hair, M. L. Langmuir 1995, 11, 149-155.

(31) Yang, H. C.; Dermody, D. L.; Xu, C.; Ricco, A. J .; Crooks, R. M. Langmuir 1996, 12, 726-735. 

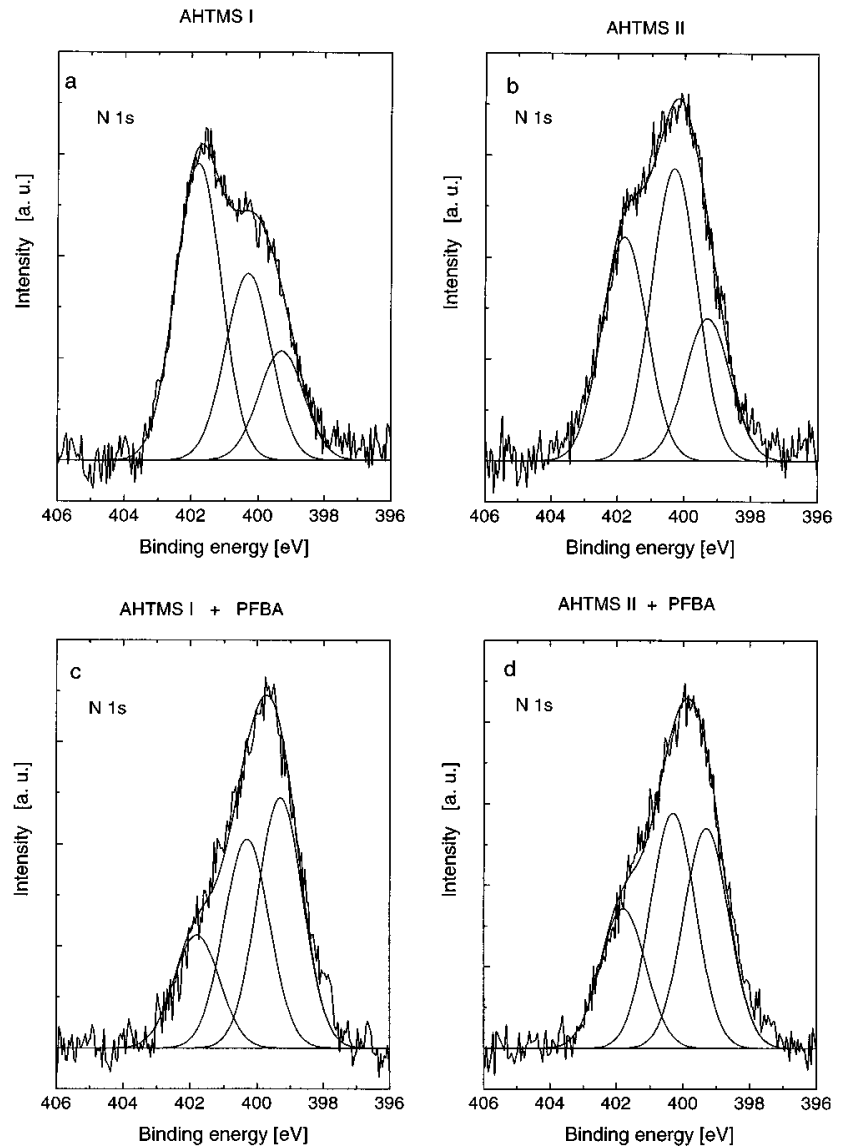

Figure 5. XPS N 1s single scans of two neat AHTMS films, prepared from the same stock solution, with a percentage of protonated nitrogen species at $\mathrm{E}_{\mathrm{b}} \sim 401.8 \mathrm{eV}$ of (a) $34 \%$ and (b) $50 \%$, and $(c, d) \mathrm{N}$ 1s scans of the same samples after coupling with pentafluorobenzal dehyde.

$35 \%$ and $50 \%$ of the total nitrogen content. For sample AHTMS I of Figure $5 \mathrm{a}$, the larger concentration of the $\mathrm{NH}_{3}{ }^{+}$species is correlated with a reduced amount of hydrogen bonded amino groups (ca. 30\% for samplel and ca. $45 \%$ for samplell ). Thepercentage of freeamino groups for both samples was about $20 \%$.

AHTMS Adsorption onto OTS Precovered Substrates. As previously reported, the properties of OTS submonolayers prepared in a chemistry laboratory atmosphere are different from the properties of samples prepared under clean room conditions. Reproducible results, with respect to the growth mode, could only be obtained in a clean room atmosphere. AFM images of OTS submonolayers prepared under clean room conditions (class 100, $21^{\circ} \mathrm{C}, 45 \%$ atmospheric humidity) reveal an island growth modefor thefilm. ${ }^{15}$ Theislands arebranched with typical diameters of $0.6-0.9 \mu \mathrm{m}$ and heights of $\mathrm{h}=$ $25.4 \pm 2.5 \AA$. With the exception of sample $A$, all of the other OTS submonolayers used in the present study were prepared in a normal chemistry laboratory. This leads to a different island size distribution. In some of the chemistry laboratory prepared series the sizes of the islands were found to be reduced to about $0.05-0.2 \mu \mathrm{m}$, while other series showed no OTS island at all in the AFM measurements. We refer to the latter as the "homogeneous" growth mode. The growth mode (AFM) and the average film thickness (XPS) before and after subsequent adsorption of AHTMS for the five different approaches used in the present study are summarized in Table 1.

The film thickness of $110 \%$ (normalized to a complete OTS monolayer) and $30 \AA$ for sample $A$, after subsequent adsorption of AHTMS, exceeds the theoretical thickness of $\sim 26 \AA$ for a monolayer with perpendicularly oriented all-trans OTS/AHTMS alkanechains. This was obviously dueto excess adsorption of physi sorbed silane, which was subsequently removed by theimmersion in PF BA/toluene and thetreatment with a cotton cl oth and solvent rinsings. Wiping of submonolayer OTS or AHTMS films with a cotton cloth was avoided because cotton fibers contain fatty acids (so-called cotton wax ${ }^{32}$ ) that might beextracted by organic solvents and strongly adsorb on high-energy surfaces.

Weexamined different procedures tocal culatetheOTS: AHTMS stoichiometry from theXPS data: Using theratio of the film thicknesses before and after subsequent adsorption of AHTMS, as determined by the attenuation of the Si $2 p$ peak, resulted in ratios for OTS:AHTMS of 5:1 (A) and 1:1 (C). However, theadded material does not show the expected $\mathrm{C}: \mathrm{N}$ ratio of 17:1 but exhibits an excess of carbon with a ratio of 25:1. The same problem was also found for neat AHTMS films, for which the ratio is also 25:1, similar tothecase of short chain aminosilanes where the surplus of carbon was even higher. ${ }^{33}$ The minimum time that was required for a precise determination of the $\mathrm{N}$ 1s intensity was about $20 \mathrm{~min}$, and we found no indication of X-ray beam damage during this time. Hence, we suggest that the organic contaminations that were adsorbed from solution or the ambient conditions during transfer onto the polar aminosilane surface are the most probable cause for the $C$ is surplus. Consequently, the calculation of the OTS:AHTMS ratio from the $C: N$ ratio of the mixed OTS/AHTMS film yiel ds a lower percentage of AHTMS, between $20 \%$ (A) and $40 \%$ (C), as compared with the estimate based on changes in film thickness. We exclude a displacement of pre-adsorbed OTS by AHTMS because weobserved noAHTMS adsorption into complete OTS films and no desorption of complete OTS films or OTS submonolayers after repeated solvent rinsings.

Figure 6 shows the $\mathrm{CH}$ stretching bands of preadsorbed OTS (left) and thecorresponding data for theOTS/AHTMS films (right). The peak positions and halfwidths of both the antisymmetric and symmetric methylene stretching modes are summarized in Table2. Normal transmission spectra yield more reliable values for the peak positions and fwhm because the anomalous dispersion influences band positions and shapes morein glancing transmission. In the case of the homogeneous growth mode films C, D, and $E$, thereis a lower limit of about $50 \%$ coverage. Bel ow that level there is a liquid-like disorder as indicated by $\mathrm{d}^{ \pm}$frequencies of 2923.5 and $2855.2 \mathrm{~cm}^{-1}$ and a dichroic ratio of $\sim 1.6$, which corresponds to an average tilt angle of $\sim 52^{\circ}$. The band positions were shifted by AHTMS adsorption to 2921.2 and $2851.8 \mathrm{~cm}^{-1}$, and the dichroic ratio decreased to $\sim 0.91$, corresponding to a tilt angle of $32^{\circ}$. The other two samples of this series with a homogenous OTS precoverage of $64 \%$ (D) and $74 \%$ (E) already show, before addition of AHTMS, peak positions which indicate a partial stretching of the alkyl chains. For these samples, the $\mathrm{d}^{-}$band positions of 2920.4 and $2919.5 \mathrm{~cm}^{-1}$, respectively, remain, within experimental error, unchanged even after addition of AHTMS. The same applies to the dichroic ratio of 0.84 and 0.66 , respectively, which corresponds to an average tilt angle of $\sim 30^{\circ}$ and $21^{\circ}$, respectively.

For samples A and B, it is problematic to calculate the average tilt angle from the dichroism of the methylene stretching modes because, in the case of island growth

(32) Römpp Chemie Lexikon, 9th ed.; Falbe, J ., Regitz, M., Eds.; Thieme Verlag: Stuttgart, 1989.

(33) Grunze, M.; Schertel, A.; Strunskus, T.; Uhrig, R.; Welle, A.; Wöll, Ch. J. Adhes., in press. 

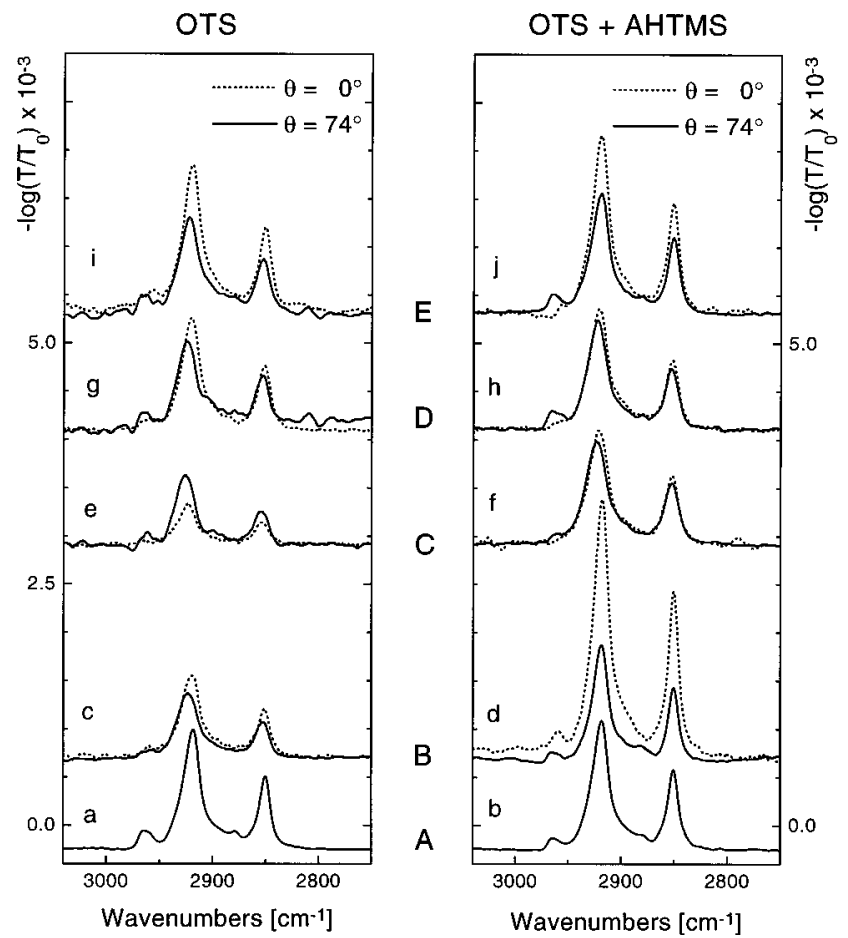

Figure 6. Transmission spectra of preadsorbed OTS submonolayer films (left) and thecorresponding OTS/AHTMS films (right) in normal (dotted curve) and glancing transmission configurations (straight curve).

mode, there might be significant deviations from the assumed refractiveindex of 1.4-1.5. In theisland model, the index of refraction is a monotonic function of the coverage, varying from 1 at zero coverage to themonolayer value at complete coverage. The identical methylene stretching peak maxima in the case of sample $A$ and the decrease in the band positions and halfwidths in the case of sample $B$, however, indicate an ordering effect of the preadsorbed OTS. For theresulting mixed OTS/AHTMS samples $A$ and $B$, the peak positions at $2918 \mathrm{~cm}^{-1}$ and lower indicatethat the percentageof gaucheconformations is within therange usually ascribed tocrystalline-ordered films. The samples of the homogeneous growth mode series do not approach that range of ordering, as indicated by the vibrational frequencies.

For mixed OTS/AHTMS sample B, the IR dichroism of 0.45 is even better than for a complete OTS film (0.55) and indicates a more dense packing of the alkane chains and a lower amount of defects for the mixed film. The dichroic ratios indicate as well that despite the resulting
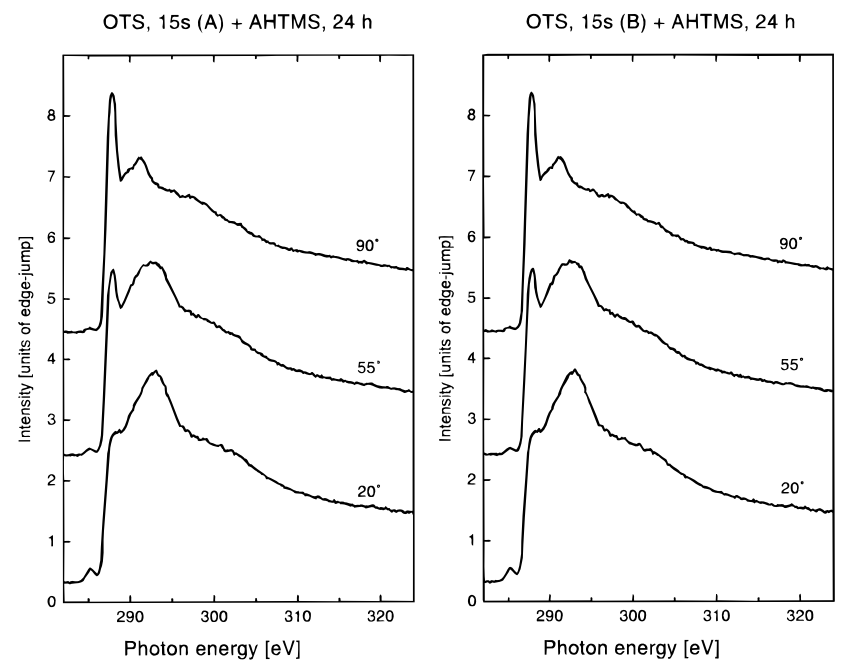

Figure 7. Series of NEXAFS spectra of mixed OTS/AHTMS films prepared by adsorption of AHTMS onto island growth OTS submonolayers A and B.

sameOTS:AHTMS stochiometry, thedegree of orientation is lower for the adsorption onto a homogeneous OTS submonolayer (C) than for theadsorption onto an al ready ordered, island growth submonolayer (B).

TheNEXAFS spectra are in qualitativeagreement with thel $R$ data and reveal a maximum dichroismfor themixed OTS/AHTMS sample B (Figure 7) and an increase of the dichroism for the homogeneous growth mode series after the sequential adsorption of AHTMS (Figure 8). The data are summarized in Table 2.

Thespectral range between 3000 and $1300 \mathrm{~cm}^{-1}$ for two OTS/AHTMS films is compared with the spectrum of a neat AHTMS film in Figure 4. Bicarbonate salt bands at 1636 and $1540 \mathrm{~cm}^{-1}$ are too weak to be detected in the OTS/AHTMS spectra. TheXPS N 1s single-scan spectra (Figure $9 a, b)$ reveal that thereis $25-30 \%$ of the protonated nitrogen species and ca. $25 \%$ of free amino groups in the mixed OTS/AHTMS films. Hence, the percentage of the protonated nitrogen species in mixed OTS/AHTMS films is lower than that in neat AHTMS films of about bilayer thickness.

Coadsorption of AHTMS with OTMS. In addition to subsequent AHTMS adsorption into the voids of submonolayer OTS films, we also investigated the simultaneous adsorption of AHTMS and long chain n-octadecyltrimethoxysilane (OTMS). The IR data (Figure 10) of a complete ( $24 \mathrm{~h}$ immersion time) OTMS film revealed that the film quality was similar to that of the corre

Table 2. IR Methylene Stretching Band Positions and Halfwidths of Samples A-E with and without Subsequent Adsorption of AHTMS, and Average Chain Orientations Determined with IR and NEXAFS Spectroscopy

\begin{tabular}{|c|c|c|c|c|c|c|c|c|}
\hline \multirow[b]{2}{*}{ sample } & \multirow[b]{2}{*}{ figure } & \multicolumn{2}{|c|}{$\mathrm{d}^{-} \mathrm{cm}^{-1}$} & \multicolumn{2}{|c|}{$\mathrm{d}^{+} \mathrm{cm}^{-1}$} & \multirow[b]{2}{*}{ dichroic ratioa } & \multicolumn{2}{|c|}{ av tilt angle (deg) } \\
\hline & & peak max & fwhm & peak max & fwhm & & IR & NEXAFS \\
\hline A & $6 a$ & $2918.2^{b}$ & $17.6^{\mathrm{b}}$ & $2850.2^{b}$ & $11.2^{b}$ & & & \\
\hline+ AHTMS & $6 b$ & $2918.1^{b}$ & $17.7^{\mathrm{b}}$ & $2850.3^{b}$ & $11.4^{b}$ & & & 39 \\
\hline B & $6 c$ & 2919.0 & 20.5 & 2851.1 & 12.2 & 0.78 & 27 & \\
\hline+ AHTMS & $6 d$ & 2917.7 & 16.1 & 2850.2 & 10.8 & 0.45 & 0 & 20 \\
\hline C & $6 e$ & 2923.5 & 21.4 & 2855.2 & 18.0 & 1.62 & 52 & $54^{b}$ \\
\hline+ AHTMS & $6 f$ & 2921.2 & 21.6 & 2851.8 & 14.4 & 0.91 & 32 & 43 \\
\hline $\mathrm{D}$ & $6 g$ & 2920.4 & 18.9 & 2851.5 & 13.5 & 0.84 & 29 & 49 \\
\hline+ AHTMS & $6 h$ & 2920.7 & 20.1 & 2851.7 & 13.0 & 0.89 & 31 & 33 \\
\hline $\mathrm{E}$ & $6 i$ & 2919.5 & 17.6 & 2850.7 & 11.8 & 0.66 & 21 & 48 \\
\hline+ AHTMS & $6 j$ & 2919.1 & 18.5 & 2850.7 & 11.8 & 0.66 & 21 & 38 \\
\hline OTS & la & 2917.7 & 16.0 & 2850.3 & 10.6 & 0.55 & 13 & $0-10$ \\
\hline AHTMS & 2 & $\geq 2918.7$ & $\geq 19.0$ & $\geq 2850.6$ & $\geq 12.3$ & $1.1-1.6$ & $38-51$ & $54^{b}$ \\
\hline
\end{tabular}

a IR $\mathrm{d}^{-}$band height at glancing incidence $\left(\theta_{\mathrm{B}}=73.7^{\circ}\right)$ divided by the band height in normal transmission $\left(\theta_{\mathrm{B}}=0^{\circ}\right)$. ${ }^{\mathrm{b}}$ Values are for glancing incidence. No spectra in normal transmission available. ${ }^{c}$ Average tilt angles close to the magic angle of $54.7^{\circ}$ can also indicate random molecular tilts, e.g., no orientational order. 

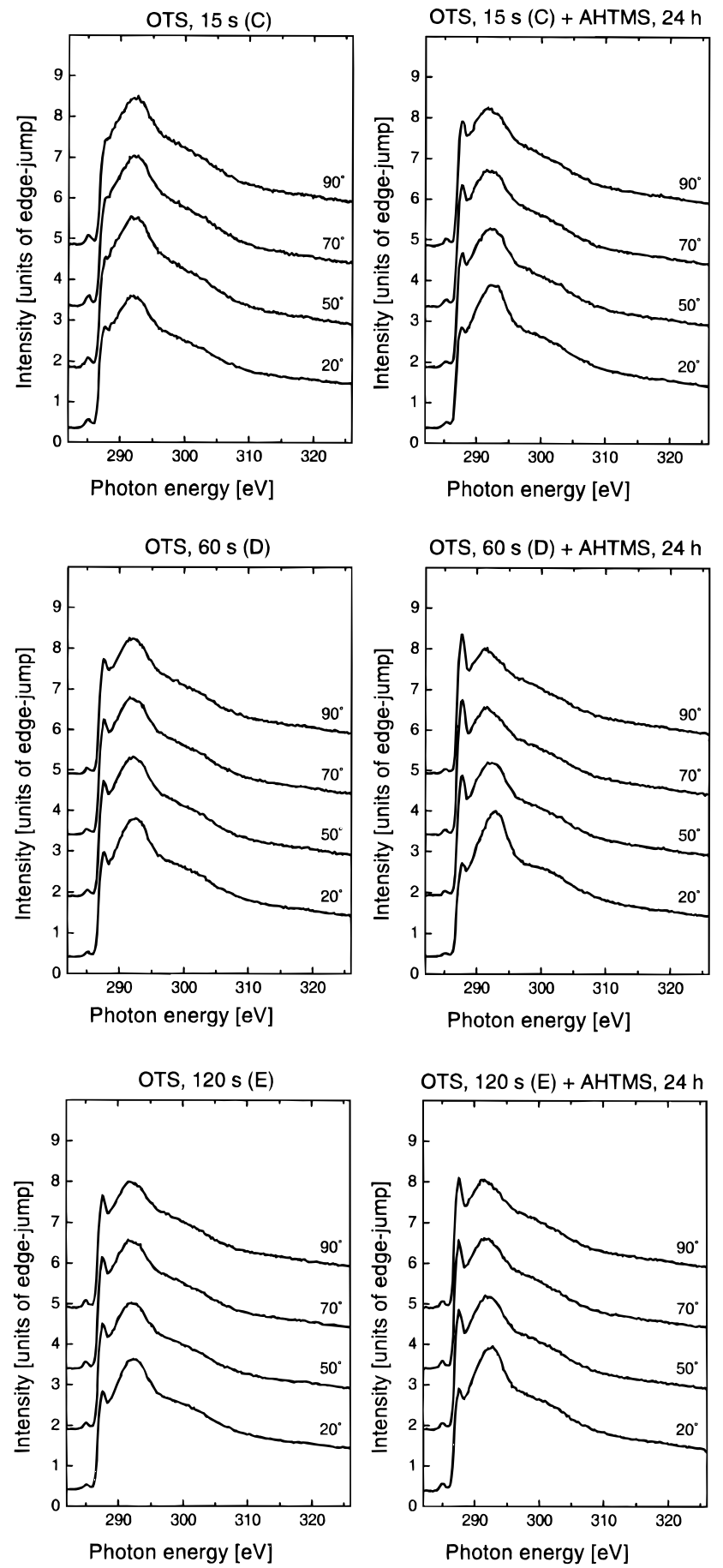

Figure 8. Series of NEXAFS spectra of OTS submonolayers $\mathrm{C}-\mathrm{E}$ and the corresponding mixed OTS/AHTMS films.

sponding trichlorosilane films. The $\mathrm{d}^{ \pm}$mode peaks of 2917.5 and $2850.1 \mathrm{~cm}^{-1}$, in combination with the appearence of the $\mathrm{CH}_{3}$ symmetric mode band in glancing transmission, strongly suggest that OTMS monolayers dominantly consist of all-trans extended chains. Mixed monolayers were prepared by coadsorption from 1:1 and $1: 3 \mathrm{v} / \mathrm{v}$ mixtures of AHTMS and OTMS at a constant total concentration of $0.1 \mathrm{M}$ in bicyclohexyl. Adsorption from the equimolar solution resulted in a ca. $32 \AA$ thick film of mainly ( 77\%) AHTMS, as determined by XPS. Similar tothefindings for neat AHTMS films, thelR peak positions of 2920.4 and $2851 \mathrm{~cm}^{-1}$ reveal ed a conformational order, despite a dichroicratio of 1.2, corresponding toan average tilt angle of ca. $40^{\circ}$. The sample that was prepared from the 1:3 AHTMS/OTMS solution resulted in a disordered submonolayer (ca. $20 \AA$ ), as indicated by XPS and $d^{ \pm}$
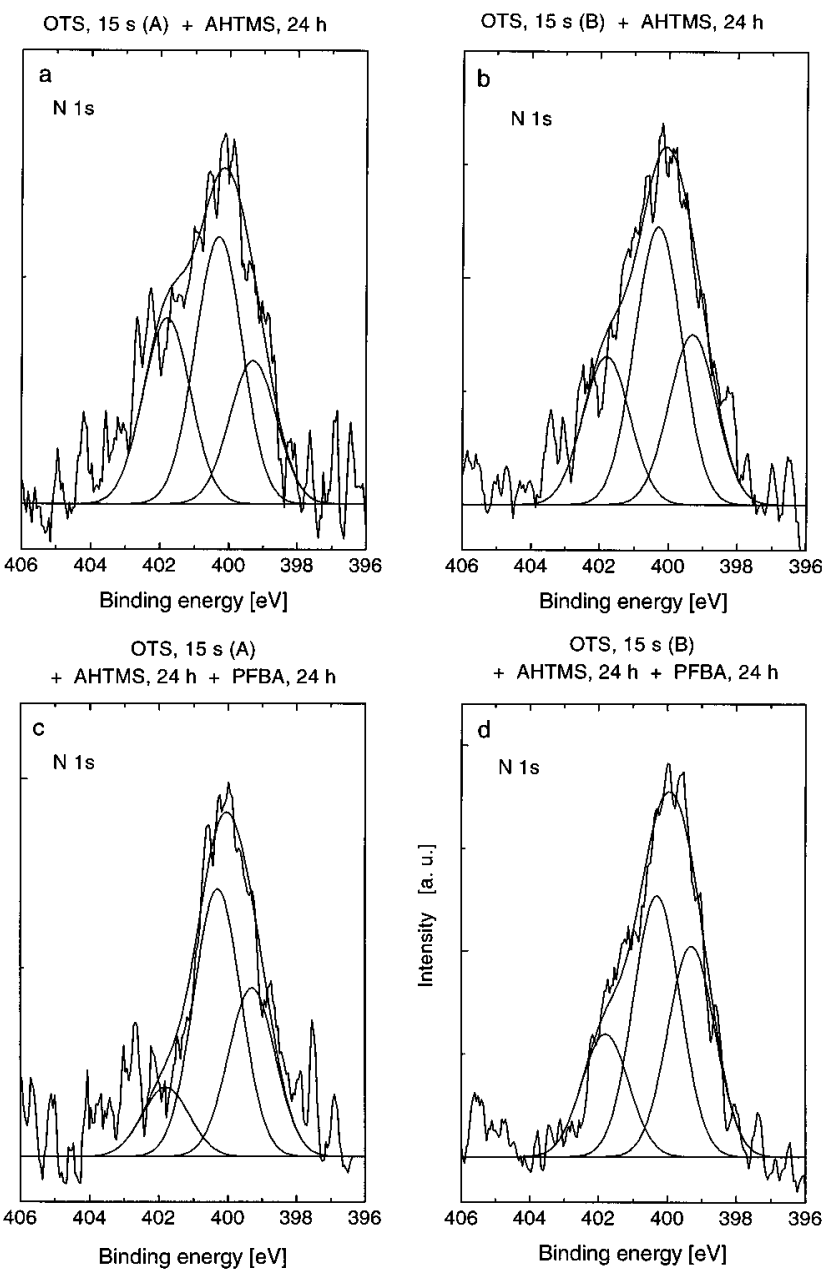

OTS, $15 \mathrm{~s}$ (B)

+ AHTMS, $24 \mathrm{~h}+$ PFBA, $24 \mathrm{~h}$

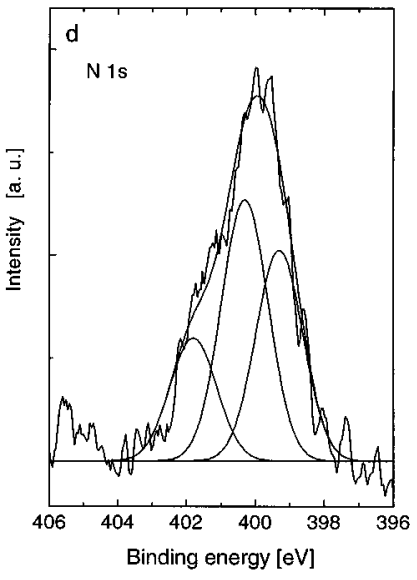

Figure 9. XPS $N$ 1s single scans of two mixed OTS/AHTMS films $(a, b)$ before and $(c, d)$ after coupling with pentafluorobenzaldehyde.

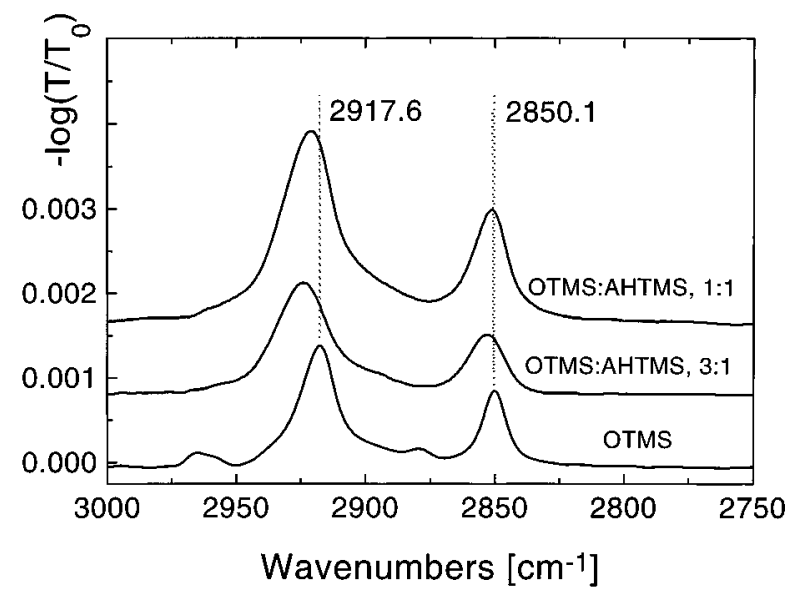

Figure 10. Glancing transmission spectra of a pure OTMS film and AHTMS coadsorbed with OTMS. The dotted line indicates the $d^{+}$and $d^{-}$mode peaks of the pure OTMS film.

mode peaks of ca. 2921.5 and $2852 \mathrm{~cm}^{-1}$, and showed a surplus ( $70 \%)$ of AHTMS.

Coupling with Pentafluorobenzaldehyde. The coupling of AHTMS films with pentafluorobenzaldehyde was studied conveniently by XPS, since fluorine is only contained in the aldehyde (Figure 11). Nitrogen/fluorine XPS intensity ratios for three neat AHTMS films with thicknesses of 39,45 , and $53 \AA$ revealed reaction rates of $21 \%, 34 \%$, and $44 \%$ for the coupling reaction with pentafluorobenzal dehyde, respectively. Comparison of $\mathrm{N}$ 1s single-scan spectra of neat AHTMS films before and 


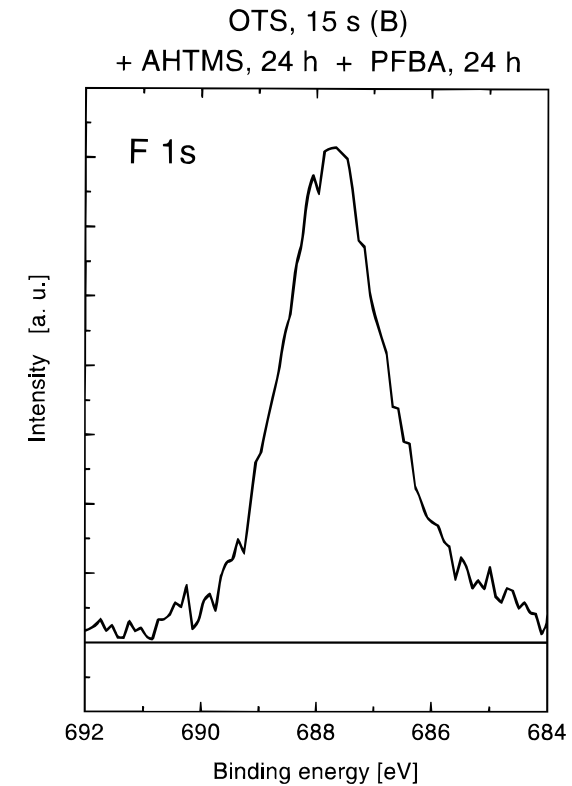

Figure 11. Singlescan XPS spectrum of the $F$ 1s region of a mixed OTS/AHTMS film after a $24 \mathrm{~h}$ immersion time in a 0.1 $\mathrm{M}$ solution of pentafluorobenzaldehyde in toluene.

after the coupling reaction (Figure 5) shows a decrease of the protonated nitrogen species from $35 \%$ to $50 \%$ to a constant level of $20-25 \%$. The $\mathrm{N}$ 1s signal of the imine nitrogen, usually observed ${ }^{34}$ at $\mathrm{E}_{\mathrm{b}} \sim 399.0 \mathrm{eV}$, overlaps with the emission of the free amine group and, hence, does not result in a new peak at a different binding energy in the spectra. The intensity of the low-binding energy imine and the free amine component increases to about $40 \%$ of the overall $\mathrm{N}$ 1s intensity, as compared to about $20 \%$ before the coupling reaction.

The IR and NEXAFS data (Table 3) of neat AHTMS films indicatenoimprovement in themolecular orientation of the alkyl chains as a consequence of the coupling reaction. As before, the band height of the IR methylene stretching modes increases by a factor of approximately 1.6 when going from normal to glancing transmission, and the NEXAFS spectra show no angular dependence, which is in accordance with a uniform tilt angle of $54.7^{\circ}$ or a random distribution of the alkyl chain orientations. A blue shift of the IR $\mathrm{d}^{ \pm}$modes of $2-3$ wavenumbers indicates, rather, that theamount of gauche confomations was significantly increased by coupling with PFBA.

Coupling reactions with mixed OTS/AHTMS samples showed (Figure 9) a turnover of $18 \%$ (sample A) and $34 \%$ (sample B) and a relative increase of the low-binding energy imine and free amine component at $399.3 \mathrm{eV}$ at theexpense of the protonated nitrogen species, as observed for the reaction of PFBA with neat AHTMS films. Compared with theXPS spectra taken before thecoupling reaction, the XPS spectra of sample $A$ after reaction revealed not only the additional $F$ 1s signal but alsoa loss of C 1s intensity by about $25 \%$, whereas the relative N 1s intensity increased. Before the coupling reaction, the mixed OTS/AHTMS film was thicker than a neat OTS monolayer (Table 1). Exposurefor $24 \mathrm{~h}$ in PF BA/toluene, followed by rinsing with water and tolueneand the wiping with a cotton cloth, seems to have removed physisorbed OTS, present before the adsorption of AHTMS. Reduced IR $\mathrm{d}^{ \pm}$hal fwidths of the methylene stretching modes for sample A after the coupling reaction (Table 2 and 3 ) are

(34) Strunskus, T.; Grunze, M.; Gnaarajan, S. In Metallization of Polymers; Sacher, E., Direux, J. J ., Kowalczysk, S. B., Eds.; ACS Symposium Series 440; American Chemical Society: Washington, DC, 1990; p 353. also in agreement with the assumption of an additional removal of excess disordered adsorption. For sample B, the higher rate was combined with a slight blue shift and an increase in the halfwidths but not with a decrease in film thickness.

After the coupling reaction, the IR dichroic ratio for mixed OTS/AHTMS films was 0.52 (A) and 0.47 (B) (Figure 12). Despite this high orientation (average tilt angles calculated from these values are $<10^{\circ}$ ), the glancing transmission spectra of sample $\mathrm{B}$ show almost no $\mathrm{CH}_{3}$ symmetric mode band of OTS at $2878 \mathrm{~cm}^{-1}$, while this band was clearly visible before the coupling (Figure $6 \mathrm{~d}$ ). NEXAF S spectra, only taken for sample $B$, show only a weak dichroism(Figure 13). A quantitativeanalysisyields an average tilt angle of $48^{\circ}$. In view of the surface sensititvity ${ }^{35}$ of the NEXAFS method, which probes only the uppermost $\sim 1.5 \mathrm{~nm}$ of the organic film, this discrepancy between the IR and NEXAFS dichroism might indicate that the coupling reaction preferentially reduces the chain orientation at the film-vacuum interface.

\section{Discussion}

Both NEXAFS and I R spectroscopy givecomplementary information about thestructure of thin organicadsorbates. NEXAFS does not havethe problems with theanomalous dispersion as IR spectroscopy does and gives direct information about the orientation of the outermost methylene units. IR spectroscopy, on the other hand, measures the whole film with the same sensitivity and gives information about the average orientation (dichroism) as well as about the average conformation (peak positions). In addition, IR spectroscopy in glancing transmission gives information on the methyl group orientation.

For neat AHTMS films, both methods are in agreement that there is no molecular orientation with respect to the suface normal. The alternative of a uniform tilt angle of approximately $54^{\circ}$ is very unlikely. Causes for themissing molecular orientation of neat AHTMS films are interactions between the amino group and the surface silanols. Molecules which are attached by both the silane head group and the amino end group prevent an orientation of thesubsequently adsor bed molecules. Thesamedoes not apply to multilayer films as indicated by IR spectra showing $\mathrm{d}^{ \pm}$peak frequencies of $<2919$ and $<2851 \mathrm{~cm}^{-1}$, close to the range of values reported for OTS films. There must besomemolecular alignment within the multilayer, contrary to physisorption of the agglomerates already polymerized in solution, which results in isotropic films, but this requires further studies.

Both preadsorption of an already aligned OTS island growth modesubmonolayer and preadsorption of a liquidlike disordered submonolayer were found to result in oriented, mixed OTS/AHTMS films. Better results, however, wereachieved with preadsorption of OTS islands.

In a chemistry laboratory environment, the island growth mode is only observed occasionally. Thevariations in the growth mode of OTS films are likely dueto airborne contaminations. Variations wereonly seen when different sample series were compared; within one sample series the results were quite consistent. The two-dimensional crystallization that leads toa solid condensed island phase might be hindered by minute quantities of surface active species, such as carbonic acids, alcohols, etc., that are always present in a chemistry laboratory environment. Despitethe differences in growth kinetics, all OTS sample preparations, after immersion times of $24 \mathrm{~h}$, resulted in

(35) Hähner, G.; Wöll, Ch.; Buck, M.; Grunze, M. Langmuir 1993 9, 1955. 
Table 3. IR Methylene Stretching Band Positions, Halfwidths, and Average Chain Orientations of OTS:AHTMS and Neat AHTMS Samples after Coupling with PFBA

\begin{tabular}{|c|c|c|c|c|c|c|c|c|}
\hline \multirow[b]{2}{*}{ sample } & \multirow[b]{2}{*}{ figure } & \multicolumn{2}{|c|}{$\mathrm{d}^{-} \mathrm{cm}^{-1}$} & \multicolumn{2}{|c|}{$\mathrm{d}^{+} \mathrm{cm}^{-1}$} & \multirow[b]{2}{*}{ dichroic ratioa } & \multicolumn{2}{|c|}{ av tilt angle (deg) } \\
\hline & & peak max & fwhm & peak max & fwhm & & IR & NEXAFS \\
\hline$A$ & $12 a$ & 2917.8 & 15.8 & 2850.1 & 10.9 & 0.52 & $<10$ & \\
\hline B & $12 \mathrm{~b}$ & 2918.5 & 17.5 & 2850.4 & 10.8 & 0.47 & 0 & 48 \\
\hline AHTMS & & 2922.5 & 24.0 & 2852.5 & 15.7 & 2.0 & 60 & $54^{b}$ \\
\hline
\end{tabular}

a IR d- band height at glancing incidence $\left(\theta_{\mathrm{B}}=73.7^{\circ}\right)$ divided by the band height in normal transmission $\left(\theta_{\mathrm{B}}=0^{\circ}\right)$. ${ }^{\mathrm{b}}$ Average tilt angles close to the magic angle of $54.7^{\circ}$ can also indicate random molecular tilts, e.g., no orientational order.

OTS, $15 \mathrm{~s}$

+ AHTMS, $24 \mathrm{~h}+$ PFBA, $24 \mathrm{~h}$

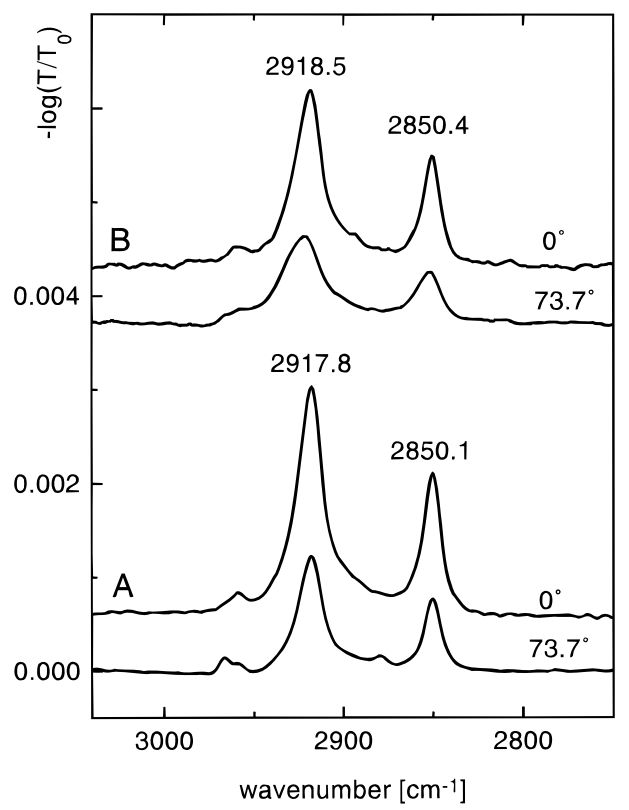

Figure 12. Normal and glancingtransmission spectra showing thetwo 15 s OTS/ $24 \mathrm{~h}$ AHTMS samples A and B after coupling with pentafluorobenzal dehyde.

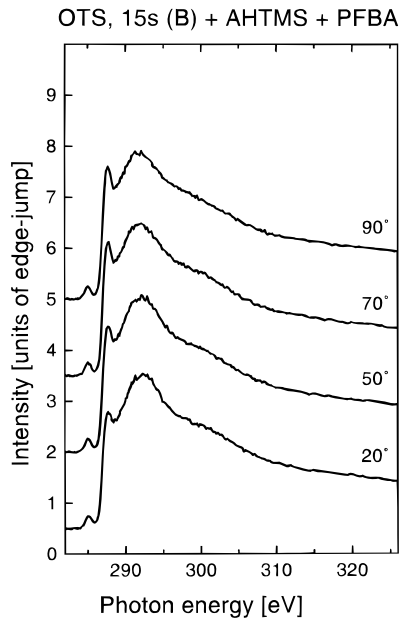

Figure 13. Series of NEXAFS spectra of the mixed OTS/ AHTMS sampleB after coupling with pentafluorobenzal dehyde. complete monolayers with an advancing water contact angle of ca. $112^{\circ}$ and identical IR spectra.

F ang and K nobler ${ }^{36}$ showed a homogeneous distribution for the sequential adsorption of perfluorinated n-decylsilane onto OTS islands that were prepared by the Langmuir-Blodgett techniqueas Iongas theislands were not heated to increase covalent bonding with surface $\mathrm{Si}-$ $\mathrm{OH}$ groups.

In our experiments, however, we cannot determinethe orientation of the AHTMS chains independently of the

(36) Fang, J .; Knobler, C. M. Langmuir 1996, 12, 1368-1374. orientation of theOTS nor thelateral distribution of OTS and AHTMS and, hence, cannot determine if an island growth mode of the preadsorbed OTS predetermines a phase separation in the mixed OTS/AHTMS films.

Sequential adsorption of OTS and AHTMS, in contrast to the simultaneous adsorption, was found to prevent excess adsorption of coagulated aminosilane. Only single AHTMS chains or smaller aggregates can fit intothevoids between theOTS chains. Therefore, thesubstratesurface is protected from flakes of polymerized aminosilane, and hence, saturation coverage is reached at monolayer thickness. For thehomogeneous OTS submonolayers, this is in agreement with previous reports ${ }^{37}$ that half a monolayer of randomly distributed $\mathrm{C}_{18}$ chains is enough to reduce the reactive area of $\mathrm{SiO}_{2}$ to $\leq 5 \%$. For theisland growth mode films, this shielding of the acid surface from AHTMS polymers implies that OTS molecules are adsorbed or physisorbed between the islands, as also concluded from a quantitative comparison between the integral coverage determined by XPS and the monolayer fraction of islands observed in the AFM measurements.

The motivation for our study of the aminosilanes is in its useas a connecting bridgefor immobilization of proteins on sensor devices. Long and short alkyl chain aminosilanes readily polymerize in solution. Hence, the film thickness is difficult to control and thesurface is a mixture of amine, methylene, methyl, and silanol groups. The covalent immobilization of proteins on these surfaces is usually done by a dial dehyde (e.g., gl utardial dehyde) that bridges aminogroups of the silanefil $m$ with aminogroups of the protein. Pentafluorobenzaldehyde, PFBA, was used as a model compound for the binding capacity of neat AHTMS and mixed OTS/AHTMS films. F or neat AHTMS films, as well as for mixed OTS/AHTMS films, we observe a reduction of the protonated nitrogen species as a consequence of the coupling with PFBA. The lower reactivity of OTS/AHTMS films, as compared to the neat AHTMS films, corresponds to a lower amount of the protonated nitrogen species before as well as after the coupling reaction. The mixing of amino-terminated and methyl-terminated end groups obviously reduces the accessibility of the amino group to $\mathrm{CO}_{2}$ and $\mathrm{H}_{2} \mathrm{O}$ to form carbamatesalts but al soreduces theability for thecoupling reaction with the aldehyde.

\section{Summary and Conclusions}

The thickness of the adsorbed neat AHTMS films was found to depend on the extent of polymerization in the solution. Because this varies strongly with age and water content of the adsorption solution, film properties were not uniform and resulted in coverages ranging from submonolayers to bilayers. With an increasing amount of physisorbed silane, the IR methylene stretching mode frequencies indicated a reduced amount of gauche conformations but no preferential orientation of the chain axes with respect to the surface normal.

(37) Allara, D. L.; Parikh, A. N.; J udge, E.J . Chem. Phys. 1994, 100, $1761-1764$ 
Adsorption of AHTMS into the voids of preadsorbed OTS submonolayer films gave mixed OTS/AHTMS monolayers with a molecular orientation equal or better tothat of the neat OTS submonolayer. Hence, it was possibleto prepare OTS/AHTMS films with an average tilt angle bel ow $20^{\circ}$ and molecular OTS:AHTMS ratios of about 2.3: 1.

It was not possible to prepare OTS templates in a reproducible way. The ordering effect for subsequently adsorbed AHTMS was found for both the island growth and homogeneous growth modefilms, but the orientation of the island growth mode preadsorbed OTS monolayers before and after subsequent adsorption of AHTMS was better than the orientation of the homogeneous growth mode submonolayers.

Coadsorption from a mixture of amino- and methylterminated silanes resulted in less ordered films and did not prevent multilayer adsorption. Hence, preadsorption of an intermediate ordered OTS submonolayer is a recommended procedure to prepare ordered, aminofunctionalized silane films of monolayer thickness.

Two coupling experiments with pentafluorobenzaldehyde as a first test for the binding capacity of a mixed OTS:AHTMS sample gave yields of $18 \%$ and $34 \%$, which compares to $21-44 \%$ for the coupling reaction with neat AHTMS films.

Acknowledgment. We are grateful to Dr. J. Sagiv, Dr. A. N. Parikh, and Dr. D. L. Allara for providing preprints of their articles. We thank the Deutsche Forschungsgemeinschaft for their support through Grant Gr 625-23 and the Fonds der Chemischen Industrie for financial support. M.G. thanks the DFG for supporting a sabbatical leave and the DAAD for a travel grant.

LA9604947 